\title{
The Online Collaborative Learning Design Webinar: A Case Study of Thai Open University's Graduate Students in a Science Education Programe
}

\author{
Songpon Phadungphatthanakoon", Duongdearn Suwanjinda, Suchin Visavateeranon \\ School of Educational Studies, Sukhothai Thammathirat Open University, Nonthaburi, 11120, Thailand
}

Received March 30, 2021; Revised April 15, 2021; Accepted June 5, 2021

\section{Cite This Paper in the following Citation Styles}

(a): [1] Songpon Phadungphatthanakoon, Duongdearn Suwanjinda, Suchin Visavateeranon, "The Online Collaborative Learning Design Webinar: A Case Study of Thai Open University's Graduate Students in a Science Education Programe," Universal Journal of Educational Research, Vol. 9, No. 6, pp. 1250-1257, 2021. DOI: 10.13189/ujer.2021.090614.

(b): Songpon Phadungphatthanakoon, Duongdearn Suwanjinda, Suchin Visavateeranon (2021). The Online Collaborative Learning Design Webinar: A Case Study of Thai Open University's Graduate Students in a Science Education Programe. Universal Journal of Educational Research, 9(6), 1250-1257. DOI: 10.13189/ujer.2021.090614.

Copyright $(2021$ by authors, all rights reserved. Authors agree that this article remains permanently open access under the terms of the Creative Commons Attribution License 4.0 International License

\begin{abstract}
In the COVID-19 pandemic situation, online education is an interesting way to enable learning anywhere. Especially in postgraduate instruction, the student's arguments, and shared knowledge and experiences with colleges are important and can be enhanced by collaborative learning activities in certain seminar courses. The purpose of this study is to evaluate the effectiveness of using the webinar on Microsoft teams considered from satisfaction towards the webinar and attitude toward MST. The participants were 40 graduate students who enrolled in a seminar in science curriculum and instruction course at Sukhothai Thammathirat Open University. The research tools were as follows: 1) A satisfaction towards the webinar questionnaire, 2) attitude toward the MST questionnaire, and 3) an interview form. The mean, standard deviation and content analysis were used for data analysis. The results of this study indicated that the vast majority of graduate students had felt satisfaction towards the webinar and attitude toward MST were scored at an overall high level. The results suggested that the collaborative learning on webinars could be an appropriate alternative to be used as supplement for traditional face-to-face learning, particularly when there is a need for locational flexibility.
\end{abstract}

Keywords Online, Collaborative Learning, Webinar, Science Education

\section{Introduction}

Online learning is becoming a very popular learning method in the present era driven by information and technology. It is often defined as any learning through electronic media such as the internet, intranet, extranet and hypertext documents or hyper media documents. It covers web-based learning, internet-based training, advanced distributing learning and online learning [1-2]. The advantages of online learning are to create a learning network that can instantly update, store or share information. Moreover, students and teachers can instantly get information through any computer connected to the internet. This learning is therefore a way of collaborative learning (CL) that helps learners and teachers to have the mental agility for learning activities [3].

$\mathrm{CL}$ is an instructional strategy focused on group activities that students learn and work together. It is a strategy encouraging students' achievement, discussion, active learning, confidence and motivation [4-5]. Thus, it is used in distance learning that stimulates virtual online communication through written texts, pictures, and videos [6]. In addition, the results of online collaborative learning (OCL) through the electronic media mentioned above help developing competence to solve problems, advanced thinking skills, group process, social skills and academic achievements [4-5]. However, for effective OCL, learning 
activities need to be designed for the context of learning which covers the learner characteristics, instructional structure and interactions [4]. The learner characteristics considered may be attitude, motivation, belief and confidence [7].

In higher education, learning how to argue one's point of view and share knowledge and experiences with others is important. Therefore, the students can learn via collaboration of teachers and peers in seminar, which is a powerful activity for collaborative learning [8].

Nowadays, the seminar was designed as virtual environment called "webinar". The webinar have gained growing attention largely and commonly applied in distance education and blended learning training programs [9-12] because, the presenter and participants from multiple sites could interact with one another through internet connections [9]. The Webinar was able to transmit text, video, audio, and images [9]. Both instructors and learners can communicate together in real time and provide feedback immediately [13]. Moreover, the instructors can facilitate participant' group collaboration in real-time [14]. Thus, the use of a webinar as OCL in higher education during the Covid-19 outbreak is a useful strategy. Meanwhile, effective learning through webinars also requires the use of effective platforms and devices. This study focused on designing OCL as a "webinar on Microsoft teams" which Microsoft teams are used as a channel for continued learning of graduate students.

The Microsoft teams (MST) is a communication platform combining chat (private or public), video meetings, file storage (including collaboration on files) and application integration. It could be installed on devices to be a channel for distance learning providing an OCL opportunity that is easy to navigate and use [15].

The purpose of this study is to evaluate the effectiveness of using the webinar on Microsoft teams based on satisfaction towards the webinar and attitude toward MST of graduate students who are enrolled in a seminar in science curriculum and instruction course at Sukhothai Thammathirat Open University.

The learners' learning satisfaction arises from external motivation, such as the satisfaction on the content the instructor, the learning strategy, devices and materials. It is the level of happiness that a person receives from learning based on goals and achievements [16], or their expectations and real experiences in learning [16-17]. The study measured learners' learning satisfaction towards the webinar in four areas which were content, learning activities, instructors, and learning channels, which was the Microsoft teams.

Attitude toward learning refer to an affective domain of learning arising from beliefs and emotions that affect the learners' academic achievement [18-19]. These consist of three components which were emotions or feelings, beliefs about the subjects, and behavioral components [20]. Hence, this study also focused on learners' attitude towards MST including the three components as mentioned earlier after participating in the webinar.

\section{Online Collaborative Learning Design (OCLD) Webinar}

The OCLD Webinar was the intervention program of this study. It was designed for OCL among students of the two-year master's degree program in science education who enrolled in a seminar in science curriculum and instruction course at Sukhothai Thammathirat Open University. The OCLD webinar lasted for 3 days. The students worked as a collaborative group to learn the role of conference organizers and participants. They exchanged and learned content, searched skills, analyzed information from academic papers, and used spoken academic English to communicate with the broader academic community. The OCLD Webinar consisted of these collaborative working activities. The collaborative reflection during their work revealed their selected role according to their interests which were divided as following:

Day 1: Attendance of a special lecture and paper presentation

Students in the seminar attended a special lecture on trends in science education. For this year's lecture, the speaker discussed computational thinking. After that, students dispersed into 5 groups of 8 , according to the issues which each person selected 1-2 months before the webinar. The five groups were Nature of Science, Science Curriculum, Science Instruction, Media and Innovation in Science Education, and Measurement and Evaluation in Science Education. In each group, for 3 hours, students presented a research article that was chosen by each individual. Teachers and friends joined the discussion.

Day 2: Introduction to international conference and online collaborations

Students joined the lectures on academic conferences for 90 minutes. Then the students spent approximately 6 hours preparing for their own academic conferences. The required elements including a title/theme of the academic conference on science education, title/theme of the 90 minutes panel discussion which consisting of 5 panelists, 1 moderator, and 2 presenters. In addition, students were required to open five online seminar rooms and make announcements about the seminar schedule for each sub-room. In each sub-room there was one moderator, 4 listeners, and 3 presenters of research articles. Three research articles were presented, 20 for presentation and 10 minutes for discussion for one paper.

\section{Day 3: Academic conference}

Students held a 3-hour academic conference on trends in science education. Each student was responsible for his or her role and duties as planned on day 2 , then a team of five lecturers provided aggregate feedback lasting for 90 minutes 


\section{Methodology}

This study used a mixed methods research design with both quantitative and qualitative parts described in the following sections.

\subsection{Quantitative Part}

This section presents the methods used in the quantitative part of the study, including a description of the participants, data collection and the statistical analysis.

\subsubsection{Participants}

The participants were 40 graduate students who were studying in the first year of a two-year master's degree program in science education, and enrolled in a seminar in science curriculum and instruction course at Sukhothai Thammathirat Open University.

\subsubsection{Data Collection}

To evaluate the satisfaction towards webinar and attitude toward MST, participants were invited to complete a satisfaction towards webinar questionnaire and an attitude toward MST questionnaire immediately after the webinar was done.

The two online questionnaires were created in Google forms. The participants' satisfaction towards the webinar questionnaire consisted of 24 items, covering the four areas which were content, learning activities, instructors, and MST. The attitude toward MST questionnaire consisted of 16 items covering the three components which were emotion or feeling, beliefs regarding to the subjects, and behaviors. These questionnaires were a 5-point Likert scale, ranged in categories from the highest, high, medium, low, and the lowest.

In addition, they were validated by five specialists and experts. Their Item-Objective Congruence Index (IOC) were calculated as Turner and Carlson [21]. Those IOC ranged between $0.60-1.00$ which were the acceptable validity.

\subsubsection{Statistical Analysis}

Descriptive statistics were used to estimate the means $(M)$ and standard deviation $(S D)$ of each item. T-test for dependent sample was used to compare mean different. An alpha level of $p<0.05$ was used for the statistical tests.

\subsection{Qualitative Part}

This section presents the methods used in the qualitative part of the study in which the participants were 10 graduate students who agreed voluntarily from the five groups of 40 participants, the detail was aforementioned in the learning activities on day 1-3. The data collection and the qualitative content analysis were described as the following.

\subsubsection{Data Collection}

\section{Interview/Focus Group}

After the webinar ended, the 10 graduate students were invited to participate in the interview. The interview was recorded digitally and transcribed the interview recording verbatim.

The 10 graduate students were asked the following five questions:

1. How do you feel about organizing a webinar on Microsoft Team?

2. In this webinar, what knowledge did you obtain? And how important is the knowledge that you obtained to your career?

3. How do you think that this webinar makes you understand the role of the academic seminar?

4. What are your opinions on activities of subgroups and main groups in the webinar, if the activities is not appropriate, do you think that how the activities should be improved?

5. What are your opinions about organizing seminars on Microsoft Teams?

\subsubsection{Qualitative Content Analysis}

The data from the interview, transcribed verbatim were analyzed by inductive processes as the procedures of Mayring [22]. They were separated into single sentences and sentence fragments and then they were coded. These codes were categorized and searched for correspondences and patterns as three themes. The themes were namely 1) Knowledge gained, 2) Learning activities, and 3) Microsoft teams. The coding scheme for qualitative content analysis provided in Table 1.

Table 1. Coding scheme for qualitative content analysis

\begin{tabular}{|c|c|c|c|}
\hline Code & $\begin{array}{c}\text { Brief } \\
\text { description }\end{array}$ & Full description & $\begin{array}{c}\text { Question } \\
\text { relate on } \\
\text { the code }\end{array}$ \\
\hline KG2 & $\begin{array}{c}\text { Knowledge } \\
\text { gained }\end{array}$ & $\begin{array}{c}\text { The code reflects the } \\
\text { students' knowledge } \\
\text { gained from the webinar. }\end{array}$ & 2 \\
\hline LA3, 4 & $\begin{array}{c}\text { Learning } \\
\text { activities }\end{array}$ & $\begin{array}{c}\text { The code reflects the } \\
\text { students' opinion on the } \\
\text { learning activities in the } \\
\text { webinar. }\end{array}$ & 3,4 \\
\hline MT1, 5 & $\begin{array}{c}\text { Microsoft } \\
\text { teams }\end{array}$ & $\begin{array}{c}\text { The code reflects the } \\
\text { students' opinion on the } \\
\text { Microsoft teams used as } \\
\text { learning activities in the } \\
\text { webinar. }\end{array}$ & 1,5 \\
\hline
\end{tabular}

\section{Results}

In this section, we present the results of the quantitative data and the qualitative data to reflect the effectiveness of webinar on MST of the study as follows. 
Table 2. Mean, standard deviation, and meaning of students' satisfaction toward webinar $(n=40)$

\begin{tabular}{|c|c|c|c|c|}
\hline No. & Items & $M$ & $S D$ & Meaning \\
\hline \multicolumn{5}{|c|}{ Satisfaction } \\
\hline \multicolumn{5}{|c|}{ Content } \\
\hline 1. & This webinar event meets the students' needs. & 4.45 & 0.50 & high \\
\hline 2. & $\begin{array}{l}\text { This webinar event helps the students understand the nature of science, curriculum, science } \\
\text { teaching, media and innovation in science instruction, measurement and evaluation of } \\
\text { science teaching and learning. }\end{array}$ & 4.33 & 0.53 & high \\
\hline 3. & $\begin{array}{l}\text { The knowledge gained from this seminar will be useful for learning in the field of science } \\
\text { the students are studying. }\end{array}$ & 4.48 & 0.51 & high \\
\hline 4. & $\begin{array}{l}\text { The students can apply the knowledge from this webinar to the development and research } \\
\text { of science curriculum and teaching. }\end{array}$ & 4.35 & 0.62 & high \\
\hline 5. & $\begin{array}{l}\text { This webinar activity promotes analytical capabilities and synthesizes research in } \\
\text { curriculum and science teaching. }\end{array}$ & 4.38 & 0.54 & high \\
\hline 6. & $\begin{array}{l}\text { This activity promotes the ability to present research work in curriculum and science } \\
\text { teaching. }\end{array}$ & 4.45 & 0.55 & high \\
\hline 7. & $\begin{array}{l}\text { This activity promotes the understanding of forms of academic seminars on science } \\
\text { curriculum and teaching. }\end{array}$ & 4.43 & 0.55 & high \\
\hline & Total & 4.41 & 0.54 & high \\
\hline \multicolumn{5}{|c|}{ Learning Activities } \\
\hline 8. & This webinar activity trains the students to work on their own and work together as a group. & 4.55 & 0.50 & highest \\
\hline 9. & $\begin{array}{l}\text { This webinar activity gives the students the opportunity to take action by allowing them to } \\
\text { jointly plan and manage the seminar according to science education issues. }\end{array}$ & 4.55 & 0.50 & highest \\
\hline 10. & $\begin{array}{l}\text { The seminar gives the students the opportunity to express themselves and ask questions } \\
\text { during the online seminar activities. }\end{array}$ & 4.53 & 0.51 & highest \\
\hline 11. & $\begin{array}{l}\text { The processes used for organizing seminars in small and large groups are suitable for } \\
\text { effective learning. }\end{array}$ & 4.38 & 0.54 & high \\
\hline 12. & $\begin{array}{l}\text { Reflection activities after the seminar allow the students to exchange their learning together } \\
\text { and benefit from additional instructor guidance. }\end{array}$ & 4.50 & 0.51 & highest \\
\hline & Total & 4.52 & 0.51 & highest \\
\hline \multicolumn{5}{|c|}{ Instructor } \\
\hline 13. & The instructors are well versed in the content. & 4.50 & 0.51 & highest \\
\hline 14. & The instructors explain the content clearly and are easy to understand. & 4.50 & 0.55 & highest \\
\hline 15. & The instructors answer the questions and give advice clearly. & 4.45 & 0.55 & high \\
\hline 16. & The instructor are very friendly with the students. & 4.55 & 0.50 & highest \\
\hline 17. & The instructors speak politely and have reliable personality. & 4.58 & 0.50 & highest \\
\hline 18. & The instructors are responsible and punctual when teaching. & 4.58 & 0.50 & highest \\
\hline 19. & The instructors are attentive and dedicated to the students' learning problems. & 4.54 & 0.51 & highest \\
\hline & Total & 4.53 & 0.51 & highest \\
\hline \multicolumn{5}{|c|}{ Learning Channel } \\
\hline 20. & The students are happy with the webinar activity through Microsoft Teams. & 4.53 & 0.51 & highest \\
\hline 21. & The webinar activities through Microsoft Teams are easy to use. & 4.48 & 0.60 & high \\
\hline 22. & Microsoft Teams webinars make it easy for the students to ask the instructors. & 4.48 & 0.51 & high \\
\hline 23. & $\begin{array}{l}\text { Microsoft Teams webinars give the students insight into the nature of science, curriculum, } \\
\text { science teaching, media and innovation in science instruction, measurement and evaluation } \\
\text { of science teaching and learning. }\end{array}$ & 4.38 & 0.54 & high \\
\hline 24. & $\begin{array}{l}\text { Microsoft Teams webinars make the students feel like they are attending face-to-face event } \\
\text { with their peers and instructors. }\end{array}$ & 4.45 & 0.64 & high \\
\hline 25. & Microsoft Teams makes it easy for the students to complete this learning activity. & 4.43 & 0.59 & high \\
\hline \multirow[t]{3}{*}{26.} & The way to submit work in Microsoft Teams is easy and convenient. & 4.45 & 0.60 & high \\
\hline & Total & 4.45 & 0.57 & high \\
\hline & Total satisfaction & 4.46 & 0.54 & high \\
\hline
\end{tabular}




\section{Quantitative Findings}

The results revealed that the satisfaction toward webinar of participants was presented in Table 2 . The data pointed out that, overall, participants were satisfied with the webinar at high level $(M=4.46, S D=0.54)$. When considering as each area of participants' satisfaction toward the webinar it was found that the participants were satisfied with learning activities $(M=4.52, S D=0.51)$ and instructors $(M=4.53, S D=0.51)$ at the highest level while they satisfied content and MST at high level.

The participants' attitude toward MST was presented in Table 3, which indicated that, overall, participants had attitude with the MST at high level $(M=4.17, S D=0.60)$.

When considering the attitude's three components in details, it is also found that the participants' attitude was at a high level in all the three areas namely beliefs regarding to the subjects $(\mathrm{M}=4.16, \mathrm{SD}=0.59)$, emotion or feeling $(\mathrm{M}=4.17, \mathrm{SD}=0.61)$, and behaviors $(\mathrm{M}=4.20$, $\mathrm{SD}=0.39)$.

Table 3. Mean, standard deviation, and meaning of students' attitude toward MST ( $=40)$

\begin{tabular}{|c|c|c|c|c|}
\hline \multicolumn{5}{|c|}{ Attitude } \\
\hline \multicolumn{5}{|c|}{ Belief } \\
\hline 1. & The students understand how Microsoft Teams works. & 4.18 & 0.55 & high \\
\hline 2. & The students understand the tools for working with Microsoft Teams. & 3.97 & 0.67 & high \\
\hline 3. & The students have the knowledge of using Microsoft Teams to manage classes. & 3.98 & 0.62 & high \\
\hline 4. & $\begin{array}{l}\text { The students think Microsoft Teams are the way to connect with social networks, such } \\
\text { as meetings, assigning works or sending reports. }\end{array}$ & 4.35 & 0.48 & high \\
\hline 5. & $\begin{array}{l}\text { The students think Microsoft Teams will be their first choice when organizing learning } \\
\text { via online channels. }\end{array}$ & 4.33 & 0.53 & high \\
\hline & Total & 4.16 & 0.59 & high \\
\hline \multicolumn{5}{|c|}{ Feeling } \\
\hline 6. & The students enjoy learning through Microsoft Teams. & 4.20 & 0.65 & high \\
\hline 7. & The students like the way Microsoft Teams work. & 4.15 & 0.53 & high \\
\hline 8. & $\begin{array}{l}\text { The students feel that Microsoft Teams is a way to quickly communicate with their } \\
\text { classmates and instructors. }\end{array}$ & 4.28 & 0.64 & high \\
\hline 9. & The students feel that Microsoft Teams is a powerful online learning channel. & 4.35 & 0.48 & high \\
\hline 10. & The students feel that using Microsoft Team is easy. & 4.23 & 0.58 & high \\
\hline 11. & The students feel that using Microsoft Team does not require advanced computer skills. & 3.95 & 0.68 & high \\
\hline 12. & $\begin{array}{l}\text { The students feel confident that the learning environment through Microsoft Teams can } \\
\text { increase the interest of the learners. }\end{array}$ & 4.15 & 0.62 & high \\
\hline 13. & $\begin{array}{l}\text { The students feel that learning through Microsoft Team has made their learning more } \\
\text { efficient compared to face-to-face learning. }\end{array}$ & 4.08 & 0.66 & high \\
\hline & Total & 4.17 & 0.61 & high \\
\hline \multicolumn{5}{|c|}{ Behavior } \\
\hline 14. & $\begin{array}{l}\text { The students often consult or collaborate with friends through Microsoft Teams during } \\
\text { learning activities. }\end{array}$ & 3.97 & 0.71 & high \\
\hline 15. & The students are very keen on doing activities through Microsoft Teams. & 4.30 & 0.46 & high \\
\hline \multirow[t]{3}{*}{16.} & $\begin{array}{l}\text { The students are able to apply their knowledge and skills in using Microsoft Teams to } \\
\text { manage their online learning for their students. }\end{array}$ & 4.33 & 0.53 & high \\
\hline & Total & 4.20 & 0.59 & high \\
\hline & Total of Attitude & 4.17 & 0.60 & high \\
\hline
\end{tabular}




\section{Interview Findings}

Knowledge gained (KG2)

Most of the participants gained more knowledge from the learning activities of Webinar which could be applied to improve their instruction, as S1 explained;

"I got a guideline for creating learning activities which can be used in teaching and learning to increase students understanding about the nature of science"

Moreover, the participants gained knowledge about Computational Thinking (CT), which was a speech title of a keynote speaker which clarified misconceptions, as two of them explained:

S1 "After listening to the speaker, I understand that CT teaching doesn't need a computer."

S2 "I originally thought that CT was only teaching about computers but when I listened to the speaker, I understood it better."

Learning activities (LA3, 4)

All participants commented that the activities in webinar promoted more understanding of various topics covering science education. Simultaneously, the activity that all participants collaborated on was the organization of the academic conference. Since the beginning, where they were inexperienced in the academic conference, the collaborative working of them could increase understanding of the academic conference context both in the role of the organizers and the participants. Their understanding was promoted while they set conference topic, scheduled and delegated roles as a seminar's operator. Below were the examples of their answers:

S3 "I understood the context of academic seminars better. And I also practiced presentation."

S4 'I gain more knowledge by attending of peers' presentations. And I understand the roles of the seminar organizers more."

Microsoft teams (learning channel) (MT1, 5)

For using MST as channel for webinar, all participants commented that MST could be a great channel which helps them to participate in learning from multiple sites. Besides, they used MST as an online learning channel before the webinar. Therefore, all participants were familiar with using the functions of MST and didn't feel that it was difficult to use, as two of them explained:

S5 "This seminar was good. I did not have to travel to study."

S6 "A previous time, we have learned through MST thus, using it in this time was not difficult."

However, most of the students reported a need to attend a face-to-face seminar especially when the university used distance learning, since they had very few opportunities to meet their friends. Therefore, they would like to learn by face-to-face with their friends more than online learning.

S7 "I think that learning in our university, we are hardly ever meet friends, thus, we should learn by face-to-face together with friends."

S8 "I agree with my friends that we should learn by face-to-face together with friends."

In addition, everyone suggested that an instruction through MST should be used for lecturing which was probably better because they gained knowledge which was not different from face to face learning, whereas a seminar should organize onsite because it requires interaction between participants to absorb the actual environment during the seminar. Besides, the participants' feelings were affected throughout the Webinar as some reported feeling lonely as reflected in the examples in their answer below.

S2 "If it's possible, online instruction via MST should be used as a lecture, because knowledge gain is not different from face-to-face learning, but face to face seminar would be great. Because I would feel real atmosphere of seminar and it would have better interaction."

S5 "Yes, I agree with S2. When I attended a lecture class, I thought it was the same as online learning but for the seminar, I wanted to participate by face-to-face onsite."

S4 "This webinar on Microsoft teams look like most of the participants rarely spoke or replied. But knowledge gained wasn't different from face to face learning."

Nevertheless, most of participants mentioned that during their attendance on the webinar, most of them did not turn on the camera and had delayed communication problem. These affected the participation atmosphere looked lonely. Those problems may be the effect of their unstable internet signal.

S5 "I did not turn on my webcam. Sometimes, my webinar was stopped because of my internet signal was poor."

S9 "I agreed with S5 on my poor internet signal which caused my delayed communication."

\section{Conclusions and Discussions}

This study contributes to assessing satisfaction towards the webinar and attitude toward MST of graduate students who enrolled the seminar in science curriculum and instruction course in the first year of master's degree program in science education at Sukhothai Thammathirat Open University. The results of this study indicated that the vast majority of graduate students had higher satisfaction towards the webinar and attitude toward MST at an overall 
at high level. Nevertheless, the findings in each area of participants' satisfaction toward the webinar revealed that the participants were satisfied with learning activities because the activity of collaborative working for academic conference organization could increase all participants' understanding of contextual factors that relate specifically to the design of online seminars and the experience of the participants. Additionally, they were also satisfied by the instructors, reported at the highest level. This finding supported the study of Zhu [23] that suggested that in online courses, the lecturer was the main partner for learning. In addition, most of participants suggested that the knowledge gained from the webinar could be applied to improve their instruction and also improved some misconceptions.

Regarding the satisfaction and attitude toward MST, all participants were satisfied and had positive attitude about MST because they were familiar with using it in online learning channels and it also helped them to participate in learning from multiple sites. This finding was consistent with the study of Cornelius and Gordon [24], Gegenfurtner, Schwab and Ebner [25] Wang and Hsu [9] which found that learners felt positive towards learning through online channels due to their ability to attend lectures at home or at their workplace without the temporal and monetary cost of traveling as the participants. However, most of the participants suggested that the seminar should be organized onsite because their university used distance learning- they had hardly opportunity to meet with their friends. Therefore, they need to experience the actual seminar environment with the peers. More importantly, their unstable internet signal obstructed the lively seminar's atmosphere because some of the peers did not turn on the camera and had delayed communication. Thus, the university and instructors should consider the internet signal problem and provide internet access from various locations for each participant in the educational process [26-27].

Summarizing the results, the collaborative learning on webinars as an alternative method was appropriate only if used as a supplement for traditional face-to-face learning, particularly when there is a need for locational flexibility.

\section{REFERENCES}

[1] Govindasamy, T. Successful Implementation of e-learning Pedagogical Considerations. The Internet and Higher Education, 4, 287-299, 2002.

[2] Khan, B. H. A Framework for Web-based Learning. Englewood Cliffs, New Jersey: Educational Technology Publications, 2000.

[3] Rosenberg, M. J. E-learning, Strategies for Delivering Knowledge in the Digital Age. New York: McGraw-Hill, 2001.
[4] Liaw, S. S. Considerations for developing Constructivist Web-based Learning. International Journal of Instructional Media, 31(3), 309-321, 2004

[5] Chen, C. M., Lee, H. M., \& Chen, Y. H. Personalized e-learning System using Item Response Theory. Computers and Education, 44, 237-255, 2005.

[6] Harasim, L. (2012). Learning theory and online technologies. New York: Routledge/Taylor \& Francis.

[7] Passerini, K., \& Granger, M. J. A Development Model for Distance Learning using the Internet. Computers and Education, 34, 1-15, 2000.

[8] Smith, B. L. \& MacGregor, J. T. What Is Collaborative Learning. The National Center on Postsecondary Teaching, Learning, and Assessment, United State: Pennsylvania State University, 1992.

[9] Wang, S.-K., \& Hsu, H.-Y. Use of the Webinar Tool (Elluminate) to Support Training: the Effects of Webinar-Learning Implementation from Student-Trainers' Perspective. Journal of Interactive Online Learning. 7, 175194, 2008

[10] Kear, K., Chetwynd, F., Williams, J. \& Donelan, H. Web Conferencing for Synchronous Online Tutorials: Perspectives of Tutors using a New Medium, Computers and Education, 58, 953-63, 2012.

[11] Stout, J. W., Smith, K., Zhou, C., Solomon, C., Dozor, A. J., Garrison, M. M. \& Mangione-Smith, R. Learning from a Distance: Effectiveness of Online Spirometry Training in Improving Asthma Care, Academic Pediatrics, 12, 88-95, 2012.

[12] Carrick, F. R., Abdulrahman, M., Hankir, A., Zayaruzny, M., Najem, K., Lungchukiet, P. \& Edwards, R. A. (2017). Randomized Controlled Study of a Remote Flipped Classroom Neuro-Otology Curriculum, Frontiers in Human Neuroscience, 8, 349, 2017.

[13] Hotcomm. Synchronous Tools and the Emerging Online Learning Model. 2003. http://hotcomm.com/tec/dlwp.pdf.

[14] Marjanovic, O. Learning and Teaching in a Synchronous Collaborative Environment. Journal of Computer Assisted Learning, 15, 129-138, 1999.

[15] Microsoft. Teams turns 2, delivers new experiences for the intelligent workplace. 2000, Retrieved 18 January 2021, from https://www.microsoft.com/en-us/microsoft-365/blog/2019/ 03/19/microsoft-teams-experiences-intelligent-workplace/

[16] Chang, I. Y., Chang, W. Y. The Effect of Student Learning Motivation on Learning Satisfaction. International Journal of Organizational Innovation, 4(3), 281-305, 2012.

[17] Topală, I. Attitudes towards Academic Learning and Learning Satisfaction in Adult Students. Procedia - Social and Behavioral Sciences, 142, 227 - 234, 2014.

[18] Triandis, H. C. Attitude and attitude change. New York: Wiley, 1971.

[19] Liaw, S. S. An Internet Survey for Perceptions of Computer and World Wide Web: Relationship, Prediction, and Difference. Computers in Human Behavior, 18(1), 17-35, 2002. 
[20] Huskinson, T. L. H., \& Haddock, G. Individual Differences in Attitude Structure and the Accessibility of the Affective and Cognitive Components of Attitude. Social Cognition, 24(4), 453-468, 2006.

[21] Turner R. C., \& Carlson L. Indexes of Item-Objective Congruence for multidimensional items, International Journal of Testing, 3)2(, 163-171, 2003.

[22] Mayring, P. Qualitative Content Analysis: Theoretical Foundation, Basic Procedures and Software Solution. Weinheim: Beltz, 2014.

[23]Zhu, C. Student Satisfaction, Performance, and Knowledge Construction in Online Collaborative Learning. Educational Technology and Society, 15(1), 127-136, 2012.

[24] Cornelius, S., \& Gordon, C. Facilitating Learning with Web Conferencing Recommendations based on Learners'
Experiences. Education and Information Technologies, 18, 275-285, 2003.

[25] Gegenfurtner, A., Schwab, N., \& Ebner, C. There's No Need to Drive from A to B": Exploring the Lived Experience of Students and Lecturers with Digital Learning in Higher Education. Bavarian Journal Applied Sciences, 4, 310-322, 2018.

[26] Chua, E. R., Sibbaluca B. G., Miranda, R. D., Palmario G. B., Moreno, R. P., \& Solon J. P. T. The Implementation of the E-Learning Classroom in Selected Higher Education Institutions in Region IV-A amidst the COVID-19 Crisis. Journal of Critical Reviews, 7(11), 253-258, 2020.

[27] Ismailova, Z. K., Kamola, R., Axmedov, M. U., Ismoilova, Y. T., \& Pulatova N. R. The Role of Electronic Pedagogical Tools in Higher Education. Journal of Critical Reviews, 7(5), 396-398, 2020. 